\title{
Carboplatin-Taxol-Bevacizumab Regimen
}

National Cancer Institute

\section{Source}

National Cancer Institute. Carboplatin-Taxol-Bevacizumab Regimen. NCI Thesaurus.

Code C63413.

A chemoimmunotherapy regimen consisting of carboplatin, paclitaxel and bevacizumab that can be used in the treatment of non-small cell lung cancer (NSCLC). 